\title{
Requalificação da Fazenda Colubandê em São Gonçalo/RJ como atrativo turístico por meio de práticas de ecoturismo e educação ambiental
}

Revitalization of the Colubandê Farm in São Gonçalo/RJ as a touristic attraction through ecoturism and environmental education practices

Recalificación de la hacienda Colubandé en São Gonçalo/RJ como atractivo turístico a través de prácticas de ecoturismo y educación ambiental DOI: http://dx.doi.org/10.18472/cvt.18n3.2018.1559

Alessandra Lopes Freitas 〈alefreitas1972@hotmail.com > Centro Federal de Educação Tecnológica Celso Suckow da Fonseca (Cefet/RJ), Rio de Janeiro, RJ, Brasil

Marco Aurélio Moura da Cunha 〈marco_m3transportes@yahoo.com.br >

Centro Federal de Educação Tecnológica Celso Suckow da Fonseca (Cefet/RJ), Rio de Janeiro, RJ, Brasil

Suellen Alice Lamas < lamas.suellena@gmail.com >

Centro Federal de Educação Tecnológica Celso Suckow da Fonseca (Cefet/RJ), Rio de Janeiro, RJ, Brasil

CRONOLOGIA DO PROCESSO EDITORIAL

Recebimento do artigo: 18 -jan-2018

Aceite: $10-$ dez-2018

FORMATO PARA CITAÇÃO DESTE ARTIGO

FREITAS, A. L.; CUNHA, M. A. M. da.; LAMAS, S. A. Requalificação da Fazenda Colubandê em São Gonçalo/RJ como atrativo turístico por meio de práticas de ecoturismo e educação ambiental. Caderno Virtual de Turismo. Dossiê temático Turismo, Natureza e Cultura: diálogos interdisciplinares e políticas públicas. Rio de Janeiro, v. 18, n. 3, p. 57-71, dez. 2018.

REALIZAÇÃO

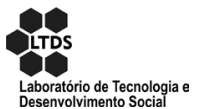

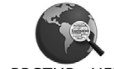

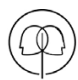

IABS
APOIO INSTITUCIONAL

COPPE

UFR]
EDIÇÃO

IFIT日R

Universidade
Federal
Fluminense

PATROCÍNIO

FAPERJ 


\section{RESUMO}

O presente trabalho apresenta um estudo de caso que visa requalificar a Fazenda Colubandê, no município de São Gonçalo/RJ, como atrativo turístico por meio de práticas de ecoturismo e educação ambiental, de modo interligado e complementar. Para tanto, utilizaram-se as técnicas de pesquisa de campo, bibliográfica e documental. É evidenciada, como resultado, a necessidade imediata de intervenção humana, tendo em vista se tratar da degradação de um patrimônio local de importância histórica, cultural, ambiental e arquitetônica. Foi proposta a requalificação do ambiente natural desse patrimônio por meio do fomento de atividades que promovam a inclusão social da comunidade e seu entorno, além de promover a reutilização e reestruturação do espaço degradado com o propósito de devolver sua identidade cultural, e torná-lo, novamente, um ambiente de entretenimento e turismo voltado às atitudes de conservação e preservação da natureza.

Palavras chave: Requalificação. Ecoturismo. Educação Ambiental.

\section{ABSTRACT}

The current work presents a case study that aims to revitalize the Colubandê Farm, in the municipality of São Gonçalo in the Rio de Janeiro state, into a touristic attraction through ecotourism and environmental education practices, in a complementary and interconnected way. Therefore, the techniques of field study, bibliographic and documentary research. The result found show the immediate need for human intervention, to treat the degradation of a local patrimony of historical, cultural, environmental and architectural importance. It was proposed that the natural environment of this site go through a process of revitalization by the way of activities that promote social inclusion of the surrounding community, as well promoting the reutilization and restructuration of the degraded site with the purpose of restoring its cultural identity, turning it back into a place for entertainment and tourism focused towards practices of conservation and preservation of nature.

Keywords: Revitalization. Ecotourism. Environmental Education.

\section{RESUMEN}

El presente trabajo presenta un estudio de caso que busca recalificar la hacienda Colubandê, en el municipio de São Gonçalo / RJ, como atractivo turístico a través de las prácticas de ecoturismo y educación ambiental, de modo interconectado y complementario. Para ello, se utilizaron las técnicas de investigación de campo, bibliográfica y documental. Se evidencia como resultado, la necesidad inmediata de intervención humana, teniendo en mente la degradación de un patrimonio local de importancia histórica, cultural, ambiental y arquitectónica. Se propuso la recalificación del ambiente natural de ese patrimonio a través del fomento de actividades que promuevan la inclusión social de la comunidad y su entorno, además de promover la reutilización y reestructuración del espacio degradado con el propósito de devolver su identidad cultural, y hacerlo de nuevo, un ambiente de entretenimiento y turismo orientado a las actitudes de conservación y preservación de la naturaleza.

Palabras clave: Recalificación. Ecoturismo. Educación Ambiental

\section{INTRODUÇÃO}

O ecoturismo é uma prática que propõe atividades em ambientes naturais, visando gerar percepção e consciência de preservação, além de interação com a natureza por parte dos turistas. Em meio a debates sobre maneiras de preservação ambiental por meio de práticas sustentáveis que envolvam o turismo, o 
Ministério do Turismo reconhece que a atividade vem se destacando nos últimos anos como um modelo de turismo mais responsável (BRASIL, 2010).

Partindo da premissa de conservação e preservação do ambiente, proposta pelo ecoturismo, este requer ações educativas, que podem ser efetivadas por meio da educação ambiental.

A discussão sobre educação ambiental no ecoturismo propõe que seu desenvolvimento se dê por meio de práticas responsáveis e participação dos cidadãos, tendo, com isso, um caráter educativo e sendo, portanto, uma importante ferramenta para o desenvolvimento sustentável do ecoturismo. Nesse sentido, como importante instrumento social, a educação ambiental se apresenta como aliada de projetos, seja de recuperação de áreas naturais ou de requalificação de espaços e patrimônio em áreas naturais.

A partir desse contexto, o presente trabalho buscou discutir a requalificação do ambiente natural da Fazenda Colubandê em São Gonçalo, estado do Rio de Janeiro, como um patrimônio histórico com atrativo turístico. Tem, portanto, como objetivo, apresentar uma proposta de requalificação para o complexo dessa Fazenda por meio de ações que envolvam ecoturismo e educação ambiental, de forma a estimular a conservação e recuperação desse patrimônio histórico e o meio ambiente em seu entorno, bem como reestimular o turismo no local. Esta proposta foi pautada na reflexão: como um patrimônio histórico pode ser requalificado a partir de práticas de ecoturismo aliadas à educação ambiental?

A escolha da área de estudo deu-se em função da degradação dos poucos pontos turísticos existentes do município de São Gonçalo/RJ e do abandono de um importante patrimônio com relevância histórica, cultural, arquitetônica e ambiental, a Fazenda Colubandê, bem como da experiência, de um dos autores, que atuou por sete anos no Batalhão de Polícia Florestal e de Meio Ambiente (BPFMA), quatro deles voltados à área de educação ambiental no Setor de Educação Ambiental (SEAmb/BPFMA).

A proposta em questão se pauta na importância cultural e ambiental do local para a comunidade e seu entorno, tendo em vista possuir espécies arbóreas ameaçadas de extinção, como o pau-brasil e o sobreiro, como observado in loco pelos autores. É relevante destacar, também, o quanto é significativa a preservação de uma área verde em local urbano, pelos inúmeros benefícios que podem trazer à comunidade, tais como: o convívio social, lazer, ambiente para o desenvolvimento de atividades educativas e práticas esportivas, melhoria do clima, qualidade do ar, água e solo, e habitat para fauna silvestre, além de poder propiciar ferramentas de pesquisa à comunidade acadêmica (NUCCI, 2008).

Vale citar ainda que este estudo complementa a decisão do Juiz Federal Fábio Teneblat, que sentenciou, em 2016, o Estado e o Instituto do Patrimônio Histórico e Artístico Nacional (Iphan) a apresentarem um projeto de restauração do patrimônio histórico da Fazenda Colubandê (ARAÚJO, 2016). Assim, enquanto a restauração do prédio será proposta pelos órgãos competentes, propomos a requalificação do ambiente natural da Fazenda.

O presente artigo decorre do Trabalho de Conclusão do Curso de Gestão de Turismo do Cefet/RJ defendido por parte dos autores no segundo semestre de 2017, que recebe o mesmo título do artigo. 


\title{
REQUALIFICAÇÃO PATRIMONIAL, EDUCAÇÃO AMBIENTAL E ECOTURISMO: ASPECTOS CONCEITUAIS
}

\section{REQUALIFICAÇÃO PATRIMONIAL}

Antes de abordarmos o tema requalificação, é necessário entender o conceito de revitalização, tendo em vista estarem interligados.

O conceito de revitalização, de acordo com Ferreira (2010), "remete a um conjunto de medidas que visam a criar nova vitalidade, a dar novo grau de eficiência a alguma coisa”. Já para Moura et al. (2006. p. 24):

\begin{abstract}
A revitalização é um processo de planejamento estratégico, capaz de reconhecer, manter e introduzir valores de forma cumulativa. Dessa maneira, ela intervém no médio e longo prazo, de forma relacional, assumindo e promovendo vínculos entre territórios, atividades e pessoas, e, por conseguinte, influencia na melhoria da qualidade do ambiente urbano e nas condições socioeconômicas.
\end{abstract}

A revitalização tem o patrimônio como parte principal, valoriza a cultura e a identidade local, e sugere a possibilidade de implantação de práticas que interessam à comunidade, como o turismo, que abrange todos esses objetivos, além de proporcionar oportunidade de desenvolvimento. Consiste na refuncionalização estratégica de áreas dotadas de patrimônio, ou seja, de objetos antigos que permaneceram inalterados no processo de transformação do espaço urbano, de forma a promover uma nova dinâmica urbana baseada na diversidade econômica e social (MOURA et al., 2006).

Em geral, as denominações que se referem à revitalização traduzem uma estratégia de valorização de áreas dotadas de patrimônios culturais que passam por processos degradativos. Em diversos países, o termo revitalização sofreu, ao longo dos anos, modificações no que diz respeito ao seu significado e surgiram vários outros com o objetivo de substituí-lo, tais como: refuncionalização, reabilitação, gentrificação ou renovação. No Brasil, a palavra é regularmente substituída por requalificação, uma vez que considera-se esse termo o mais adequado ao conceito de inclusão social, uma proposta mais humanizada, participativa e representativa da comunidade do que o sentido excludente do termo revitalização (SOTRATTI, 2015).

Esses processos de refuncionalização do patrimônio são tendência no País. De acordo com Silva e Pinheiro (2014, p. 177):

No Brasil, ao longo dos anos, vem crescendo o movimento de intervenção nos centros e espaços urbanos, com o objetivo de deixá-los em condições de melhor uso pela população local e por visitantes que estão em busca de conhecer novos lugares e culturas.

Entre os exemplos de requalificação, podemos citar o Programa Corredor Cultural no Rio de Janeiro, os programas de recuperação das áreas centrais de São Luís, no Maranhão, da cidade de Santos, em São Paulo, e do Pelourinho, na Bahia (MARINS, 2018). Um outro exemplo é a requalificação da área natural de Acajatuba, Amazonas, realizada pelo Núcleo de Educação Ambiental Acajatuba (AMAZÔNIA REALIDADE, 2015).

Cabe elucidar que tais conceitos, de revitalização e requalificação, usuais na área de patrimônio e história, são apropriados neste trabalho para aplicação no contexto ambiental de um atrativo turístico. 


\section{EDUCAÇÃO AMBIENTAL}

Educação ambiental é um conceito em construção, que apresenta várias definições, assim como o de meio ambiente esteve, em seu início, atrelado à ideia de natureza, uma corrente conservacionista. No entanto, tem sido incorporado a ele as dimensões socioeconômica, política, cultural e histórica (BRASIL, 2001). De acordo com Dias (2010, p. 98), "a evolução dos conceitos de educação ambiental esteve diretamente relacionada à evolução do conceito de meio ambiente e ao modo como este era percebido". Apresentamos, a seguir, algumas definições consideradas como marcos nessa discussão.

Segundo Sato (1997), a definição mais conhecida de educação ambiental foi apresentada durante a Conferência Intergovernamental em Educação Ambiental aos Países-Membros, realizada em Tbilisi, Geórgia, no ano de 1977. Segundo a autora:

A educação ambiental é um processo de reconhecimento de valores e clarificação de conceitos, objetivando o desenvolvimento das habilidades e modificando as atitudes em relação ao meio, para entender e apreciar as inter-relações entre os seres humanos, suas culturas e seus meios biofísicos. A educação ambiental também está relacionada com a prática das tomadas de decisões e a ética que conduzem para a melhoria da qualidade de vida (SATO, 1997, p. 86).

O Tratado de Educação Ambiental para Sociedades Sustentáveis e Responsabilidade Global, de 1992, documento elaborado durante a Conferência das Nações Unidas sobre o Meio Ambiente e Desenvolvimento (RIO 92) e ratificado pelo novo encontro da RIO+20 em 2012 (ONU, 2012), reconhece a educação ambiental como:

[...] um processo de aprendizagem permanente, baseado no respeito a todas as formas de vida, afirmando valores e ações que contribuem para a transformação humana e social e para a proteção ambiental. Estimula a formação de sociedades socialmente justas e ecologicamente equilibradas, que conservem entre si relação de interdependência e diversidade, o que requer responsabilidade individual e coletiva local, nacional e mundial (BRASIL, 2010, p. 23).

A Política Nacional de Educação Ambiental, Lei no 9.795 de 1999, por sua vez, em seu artigo 1º, define a educação ambiental como:

[...] os processos por meio dos quais o indivíduo e a coletividade constroem valores sociais, conhecimentos, habilidades, atitudes e competências voltadas para a conservação do meio ambiente, bem de uso comum do povo, essencial à sadia qualidade de vida e sua sustentabilidade (BRASIL, 1999).

As definições de educação ambiental são muitas e variadas, em comum a elas podemos citar a abordagem sistemática (integradora e holística) das questões ambientais. Assim, entendemos que a educação ambiental se apresenta como um procedimento para elucidação de valores e adoção de práticas de construção de uma sociedade igualitária, de respeito à vida, garantindo um meio ambiente equilibrado para as atuais e futuras gerações.

\section{ECOTURISMO}

Segundo o Ministério do Turismo (MTur), o ecoturismo se fundamenta na organização dos espaços a serem visitados e não apenas no comportamento do turista. Deve haver respeito pela cultura e identidade local, observando os princípios da conservação, preservação, manejo e restrição do fluxo de visitantes com o objetivo de minimizar os impactos ao meio ambiente. É necessária, também, a promoção de informações acerca do ambiente natural e sua cultura, conhecido como interpretação ambiental, além da educação ambiental, a fim de aguçar a consciência sustentável (BRASIL, 2010). 
Em 1994, foi publicado, pela então Empresa Brasileira de Turismo (Embratur), o documento "Diretrizes para uma Política Nacional de Ecoturismo" que definiu esse conceito, o de ecoturismo, em substituição ao de turismo ecológico (BRASIL, 2010). A saber:

\footnotetext{
Dessa forma, para fins de implementação de uma política nacional, conceitua-se, neste documento, o ecoturismo como "um segmento da atividade turística que utiliza, de forma sustentável, o patrimônio natural e cultural, incentiva sua conservação e busca a formação de uma consciência ambientalista por meio da interpretação do ambiente, promovendo o bem-estar das populações envolvidas" (BRASIL, 1994, p. 19).
}

O ecoturismo, portanto, não é visto apenas como uma forma de desempenhar atividades em espaços naturais, mas também para conscientizar a reconstrução de espaços degradados. A motivação para fazê-lo está ainda nos serviços oferecidos no destino, tais como hospedagem, alimentação e demais atrativos voltados à sustentabilidade. Dessa forma, a comunidade receptora pode contar com um maior desenvolvimento econômico, por meio da interligação entre as atividades em áreas naturais e atrativos do local de destino, sem que haja grandes modificações no ambiente em questão (MAGALHÃES, 2001).

Vale ressaltar que a atividade turística deve ser controlada também em áreas de prática de ecoturismo, tendo em vista os impactos negativos que este pode causar ao meio ambiente, tais como: acúmulo de lixo, poluição sonora, solo impactado, destruição da vegetação, caça e pesca ilegais, além de possíveis incêndios ocasionados pelo uso desordenado de fósforos e isqueiros (RUSCHMANN, 1993).

Para o MTur, as principais atividades relacionadas ao ecoturismo são: observação de flora e formações geológicas, visitas a cavernas, mergulho livre, caminhadas ecológicas, trilhas interpretativas e safáris fotográficos (BRASIL, 2010).

Com o objetivo de conscientizar o turista em relação à conservação do meio ambiente, vê-se a possibilidade de aliar o ecoturismo à educação ambiental. As experiências ecoturísticas possuem elevado potencial para a interiorização de princípios da educação ambiental, pois “[...] promovem o aprimoramento das relações dos indivíduos consigo mesmos e auxiliam a tornar conscientes as relações que as pessoas têm umas com as outras e com o meio natural" (MENDONÇA, 2005, p. 537).

Uma vez elucidados os conceitos de ecoturismo e educação ambiental que norteiam a presente proposta de requalificação, faz-se necessário conhecer um pouco sobre a Fazenda Colubandê, área de estudo deste artigo.

\section{ÁREA DE ESTUDO: FAZENDA COLUBANDÊ}

No final do século XVI, houve o desmembramento do município de São Gonçalo/RJ pelos jesuítas e a instalação de uma fazenda na região denominada Colubandê. A princípio, a fazenda recebeu o nome de Engenho Nossa Senhora de Mont'Serrat, um dos mais produtivos do País. Em seguida, teve seu nome modificado para Engenho Colubandê e, hoje, Fazenda Colubandê (PMSG, 2017; SOS COLUBANDÊ, 2017).

A Fazenda Colubandê é considerada um importante exemplar da arquitetura rural brasileira, tombada pelo Instituto do Patrimônio Histórico e Artístico Nacional (Iphan), em 23 de março de 1940, como bem cultural - Processo 212 de 1939 (IPHAN, 2018). A casa principal apresenta uma construção em estilo colonial, com paredes de até 1,5 metro de espessura. Possuía 38 cômodos, incluindo os quatro do 
subsolo, onde ficavam os escravos. O poço localizado no térreo servia para abastecer o casarão. Próximo à casa, na área onde foi construída uma piscina, existe um mural em homenagem às mulheres, obra da artista plástica Djanira, datada de 1960 (BELTRÃO, 2017).

Anexa à casa principal existe, ainda, uma capela, também em estilo colonial, denominada Capela de Sant’Anna, que possui painéis em azulejaria portuguesa em estilo rococó, que retrata, à direita, o pedido de casamento de São Joaquim à Sant'Ana e, à esquerda, Sant'Ana ensinando Maria a ler. Possui frontão triangular e uma torre com teto abobadado (SOS COLUBANDÊ, 2017). A capela e o casarão são ilustrados na Figura 1.

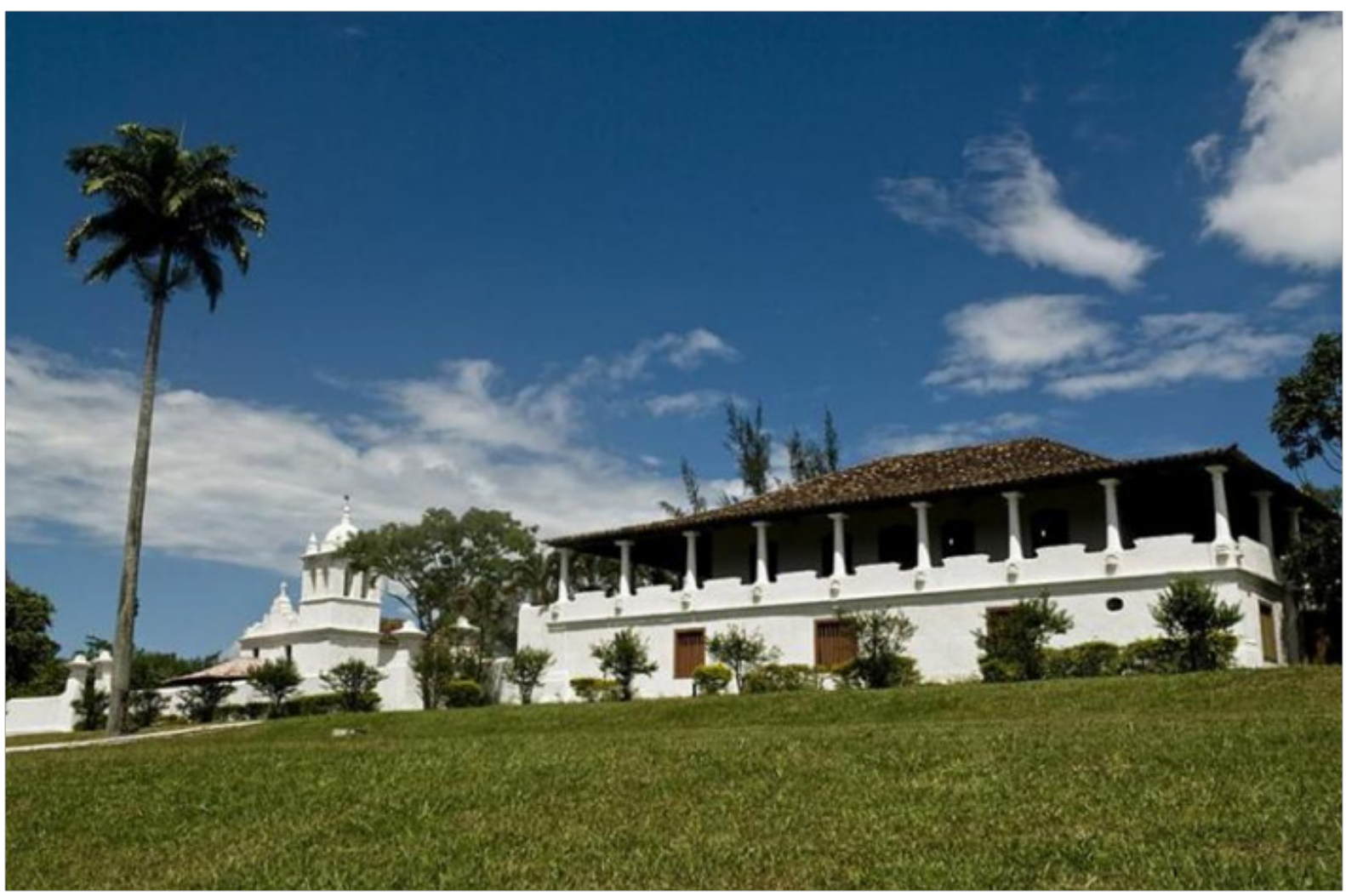

Figura 1 - Fazenda Colubandê: Capela de Sant’Anna (à esquerda) e Casarão (à direita) Fonte: Isabela Kassow (2014)

Com vasta área verde, ainda possui árvores de pau-brasil, plantadas à época de sua construção no século XVII, datada provavelmente de 1618, além de ter sido considerada a maior produtora de cana-deaçúcar da região. Teve como último dono o Coronel Belarmino Ricardo Siqueira, o Barão de São Gonçalo (BELTRÃO, 2017; ICMBIO, 2017).

Ocupando $122.141 \mathrm{~m} 2$ de área verde, abrigou, em 1969, o Corpo de Policiamento Militar e, a partir de 1988, o Batalhão de Polícia Florestal e de Meio Ambiente (BPFMA), pertencente à Polícia Militar do Estado do Rio de Janeiro (PMERJ). Em julho de 2012, com a criação e transferência do Comando de Policiamento Ambiental (CPAm) para as instalações do Comando de Polícia Pacificadora (CPP), a fazenda ficou abandonada (SOS COLUBANDÊ, 2017).

A partir da saída da Polícia Militar do local em 2012, a Fazenda foi invadida e saqueada por vândalos, parte do teto da capela desabou, mobiliários, lustres, disjuntores, torneiras e peças centenárias foram 
furtadas, outras religiões estão utilizando a capela para depositar suas imagens e casais utilizam o local para namorar. Uma ronda policial, pertencente ao $7^{\circ}$ Batalhão de Polícia Militar ( $\left.7^{\circ} \mathrm{BPM}\right)$, passou a ser realizada no local, porém, não foi suficiente para impedir a depredação do patrimônio (ARAÚJO, 2016).

De acordo com publicação no Diário Oficial do Estado do Rio de Janeiro no 161, parte I, datada de 29 de agosto de 2017, a Secretaria de Segurança Pública (Seseg) passou a desempenhar o papel de gestora da Fazenda Colubandê, tornando-se responsável pela guarda, conservação e manutenção do imóvel em sua totalidade (RIO DE JANEIRO, 2017).

Existe um projeto de retorno do $(\mathrm{CPAm})$ às instalações da Fazenda Colubandê, porém, será de maneira gradativa, tendo em vista a necessidade de captação de recursos para a restauração desse patrimônio $(O$ SÃO GONÇALO, 2017).

\section{METODOLOGIA}

O presente artigo caracteriza-se como um estudo exploratório que busca a aplicação de práticas dirigidas a soluções de problemas específicos. Desse modo, buscou-se a requalificação da Fazenda Colubandê por meio da educação ambiental e do ecoturismo, de modo interligado e complementar. Trata-se, portanto, de um estudo de caso. Vale destacar que a proposta não é a de restauração da parte física do patrimônio, mas de requalificação de seu espaço externo (ambiente natural), visando despertar o interesse da sociedade a fim de participar ativamente das atividades educacionais e turísticas oferecidas.

A respeito da coleta de dados, a pesquisa contou com três etapas. A primeira abrangeu consultas à internet e pesquisas bibliográficas, com o objetivo de aprofundar os conhecimentos acerca do objeto estudado e o meio que o cerca, a fim de promover a fundamentação das informações contidas no presente artigo. A segunda etapa contou com pesquisa de campo, com a intenção de observar o espaço e demonstrar o estado atual do patrimônio, complementando, assim, a parte teórica. Na terceira etapa foi aplicado um questionário ao Comandante do CPAm, o Coronel da Polícia Militar (Cel. PM) Mário Márcio Pereira Fernandes, levando em consideração o possível retorno da instituição às instalações do complexo. $\mathrm{O}$ questionário, realizado em 25 de outubro de 2017, teve como objetivo complementar a presente pesquisa, por meio de indagações sobre possíveis projetos a serem implementados na Fazenda Colubandê e a opinião sobre as questões inerentes ao ecoturismo e educação ambiental para a requalificação da Fazenda, proposta neste trabalho.

Foi realizada a tentativa de entrevista com representantes do Instituto Estadual do Patrimônio Cultural (Inepac), Iphan e Seseg, sendo que esta última nos informou à época que a responsabilidade pela Fazenda Colubandê foi transferida para a Subsecretaria de Gestão e de Superintendência de Patrimônio. Foi feito contato com essa Subsecretaria e fomos informados que, por conta da crise no estado do Rio de Janeiro, não havia funcionários aptos a nos conceder uma entrevista e, por esse motivo, não poderiam nos atender. Ainda assim enviamos e-mails na expectativa de conseguir a entrevista mesmo a distância, porém, não recebemos respostas. 


\section{RESULTADOS}

\section{PERCEPÇÕES DO “FUTURO” GESTOR}

Diante da possibilidade de retorno da PMERJ à Fazenda Colubandê, ainda na gestão do governador Luiz Fernando Pezão, eleito no ano de 2014, foi realizado um questionário com o Cel. PM Mário Márcio Pereira Fernandes, o possível "futuro" gestor da Fazenda.

O Cel. Fernandes foi indagado inicialmente sobre a existência de alguma proposta de revitalização da Fazenda Colubandê e, em caso positivo, quais atividades envolveria. Ele respondeu que "sim, há pelo Governo do Estado a intenção de recuperação da fazenda Colubandê. Seriam atividades de reforma e restauro do prédio" (FERNANDES, 2017). Vale lembrar que essa resposta confirma a sentença expedida pelo Juiz Federal Fábio Tenenblat, em 2016, citada na Introdução (ARAÚJO, 2016).

Quando questionado se a implementação de um projeto de requalificação da Fazenda envolvendo as atividades de ecoturismo e educação ambiental traria benefícios à comunidade local, o Cel. Fernandes respondeu que "seria um grande ganho de lazer e entretenimento para o bairro e toda a São Gonçalo" (FERNANDES, 2017).

De acordo com o Cel. Fernandes, ao ser indagado se a comunidade se envolveria em um projeto voltado à proposta de ecoturismo e educação ambiental, afirmou que "na época do Batalhão Florestal na fazenda, era grande a participação da comunidade e, isso, com certeza, iria se repetir" (FERNANDES, 2017). Ao ser perguntado se existe interesse para que a Fazenda volte a ser um ponto turístico, falou que o local possui um grande potencial para o turismo, demonstrando, com isso, tal interesse pela PMERJ.

Sobre qual a importância dos recursos naturais presentes na Fazenda para a comunidade acadêmica, o Cel. Fernandes (2017) expressou que "A fazenda é um ícone da arquitetura colonial e um testemunho da História do Brasil, tem grande relevância para as ciências que têm como objeto de estudo testemunhos como esse".

A respeito de qual a previsão do retorno do CPAm às instalações da Fazenda Colubandê, relatou que "o retorno depende do início das obras e destinação de recursos para o início da reforma" (FERNANDES, 2017). Não existe, portanto, uma previsão para o início das obras, pois há a necessidade de captação de recursos para isso.

Finalmente, ao ser perguntado sobre a importância para o município de São Gonçalo de se preservar um patrimônio como a Fazenda Colubandê, respondeu: "Muito grande. São Gonçalo carece de espaços de cultura e de lazer" (FERNANDES, 2017). E, no tocante ao que se perdeu com a invasão da Fazenda, após a saída do BPFMA, em 2012, o Cel. Fernandes (2017) declara que "Infelizmente este testemunho da História foi muito degradado com a saída do BPFMA, o maior exemplo disso foi o furto do altar da capela, como várias outras coisas e objetos que se foram, destruindo e descaracterizando o bem tombado".

Diante do cenário atual em que se apresenta a Fazenda Colubandê, descrevemos, na seção a seguir, propostas para a requalificação daquele espaço como atrativo turístico por meio do binômio ecoturismo e educação ambiental, de modo correlacional. 


\section{PROPOSTAS PARA A REQUALIFICAÇÃO DA FAZENDA COLUBANDÊ COMO ATRATIVO TURÍSTICO}

A proposta a ser apresentada consiste no desenvolvimento de atividades pautadas no ecoturismo e educação ambiental a serem realizadas em uma área degradada, buscando a valorização da Fazenda Colubandê, utilizando-se a requalificação do seu ambiente natural como ponto-chave nesse processo.

Tal proposta é alicerçada pelos estudos de Pelegrini (2006) que destaca como as relações entre natureza e cultura têm norteado ações no âmbito da educação patrimonial e ambiental tornando-se instrumentos para a construção da cidadania e do desenvolvimento sustentável.

\section{Educação Ambiental}

Ao se trabalhar a educação ambiental é importante repensar de que maneira pode-se contribuir efetivamente, não estando-se preso somente à ideia de proteger e conservar a natureza, mas também construir novos estilos, permitindo então manifestações culturais, desenvolvendo potencialidades individuais e coletivas. Daí a importância de se conhecer a realidade local, pois assim serão definidos os meios pelos quais se darão a informação e formação. Nesse sentido, Mussara (2016) contribui ao afirmar que bens culturais são constantemente recriados pelas comunidades em função de sua interação com a natureza e sua história, visando a continuidade de sua identidade, o que pode ser fomentado pela educação ambiental no contexto da Fazenda Colubandê.

Em visita à Fazenda Colubandê, foi observado que já existe interesse da comunidade em utilizar aquela área. $\mathrm{Na}$ ocasião do feriado de 12 de outubro de 2017, estavam sendo realizadas competições esportivas com crianças e adolescentes; adultos caminhavam pelo que ainda resta de trilhas e que sobrevivem à degradação, e ciclistas aproveitavam o que resta das ruas de paralelo que resistem ao crescimento da vegetação.

A intenção, a partir desta observação direta, é que a comunidade passe a ver a Fazenda Colubandê para além de um centro de práticas esportivas, como um local para lazer e aprendizado, por meio das atividades de educação ambiental, podendo ser acrescentado ao local placas que expliquem sobre as espécies arbóreas que se encontram ameaçadas de extinção, remanescentes na Fazenda.

Propomos também a participação das escolas do município e, em especial, as três localizadas no bairro Colubandê para uma educação ambiental além da sala de aula, com a participação efetiva, por meio de atividades que possam fazer parte da rotina de cada escola, mediante visitação contínua, sendo utilizado um calendário que possa manter os alunos atuantes durante todo o ano. As atividades voltadas à educação ambiental podem incluir o replantio de mudas de espécies nativas da Mata Atlântica; passeios guiados pelas trilhas, mapeando todo o local; noções de coleta seletiva, criando, assim, uma consciência de preservação e, como já foi abordado, a realização de eventos culturais que venham potencializar a participação da comunidade e seu entorno, tais como cine ambiental ao ar livre e visita guiada às dependências da Fazenda, a fim de conhecerem melhor sua história.

Um exemplo positivo da utilização da educação ambiental que leve em consideração práticas transformadas em defesa do patrimônio natural e cultural é apresentado nos estudos de Schimanski, Moreira e Moro (2013). Os autores avaliaram a região de Piraí da Serra/PR que apresentava processos sucessivos de degradação. Nesse cenário, propostas de educação ambiental de caráter crítico e transformador tornaramse imprescindíveis para a preservação da região. 
As atividades de educação ambiental devem ser estendidas aos turistas e à comunidade, nas quais, além do replantio de mudas, há a possibilidade de indicar os locais corretos para descarte dos resíduos, e, para isso, seria importante a distribuição de recipientes para que os visitantes façam o seu descarte e, no final da atividade, os coloquem nos locais corretos.

A Fazenda poderia também ser utilizada futuramente para estudos da comunidade acadêmica, como os grupos de pesquisa que trabalham com a temática de patrimônio cultural. De acordo com o Diretório dos Grupos de Pesquisa do Conselho Nacional de Desenvolvimento Científico e Tecnológico (CNPq), há na Região Sudeste do Brasil 148 grupos atuantes nesse tema, sendo 44 deles no Estado do Rio de Janeiro (CNPQ, 2018).

Nesse sentido, pensamos a educação ambiental como prática complementar à educação formal, que permite a inclusão social tanto de escolas quanto de turistas e moradores locais.

\section{Ecoturismo}

As atividades a serem apresentadas têm como objetivo criar uma consciência ambiental nas comunidades acadêmica e local, e em visitantes, gerando assim uma responsabilização continuada para que os participantes tenham noções básicas de educação ambiental e possam fazer de maneira responsável as práticas de ecoturismo na Fazenda Colubandê.

Uma atividade importante que alia o ecoturismo à educação ambiental, seria a trilha interpretativa que tem como funções, além do entretenimento, ampliar as noções de conservação, gerar a consciência no visitante para o local visitado, buscando aumentar a sensibilização e o sentido de preservação, a fim de promover a redução dos impactos negativos causados pela visitação.

De acordo com Silva et al. (2011), as trilhas interpretativas envolvem diferentes atividades de sensibilização ambiental, incluindo práticas de relaxamento e observação de paisagens em uma verdadeira relação de sentir e fazer. Desse modo, conforme expõem Silva et al. (2016), um percurso interpretativo para fins turísticos e de educação patrimonial cria laços, conexões e afetividades esquecidas ou não conhecidas.

A contribuição inicial desta proposta consiste em despertar na comunidade e, consequentemente, nos visitantes, o sentimento de importância da história e tudo que envolve a Fazenda, dando assim sentido de pertencimento ao meio e relevância ao projeto. Uma atividade cultural, como a visita guiada às dependências da Fazenda Colubandê, despertaria nos turistas e moradores a consciência sobre a importância de ter, preservar e conservar esse patrimônio de relevância histórica, cultural e ambiental.

Nessa perspectiva verifica-se que, em longo prazo, empregos poderiam ser criados, reduzindo-se desigualdades e promovendo a inclusão social com a utilização sustentável do patrimônio material, tal qual como expõem Argôlo e Bomfim (2008) que acreditam na efetivação de uma atividade turística sustentável com uma turística cultural associadas à necessidade de desenvolvimento sustentável das comunidades locais.

Para o desenvolvimento do ecoturismo existem algumas atividades que podem ser praticadas na Fazenda Colubandê, tais como: caminhadas - percursos predefinidos realizados a pé; trilhas interpretativas - percurso predefinido com identificação dos pontos mais importantes, destacando, ao longo do trajeto, quais cuidados devem ser tomados para que os impactos causados pelas visitações sejam reduzidos; observação de fauna - observação direta dos animais (aves, insetos, répteis, anfíbios e mamíferos); observação da flora - observação das plantas existentes no local, com aprendizado daquelas que podem 
ser utilizadas para a obtenção de remédios naturais, além das ameaçadas de extinção, sendo essa vertente do turismo voltada para apreciação da natureza de forma ecologicamente correta e consciente.

Para Narvaez (2014), para uma localidade desenvolver o ecoturismo é preciso atentar para fatoreschave desse processo, como a coesão entre os diferentes atores locais e o compromisso com o local, sua cultura, identidade e recursos naturais.

O resultado esperado para o desenvolvimento do ecoturismo na Fazenda e o baixo impacto ambiental aliado ao que já foi proposto com a educação ambiental, seguem, assim, com a requalificação do local, já que nesse modelo, mesmo que ocorra alteração no ambiente durante a visitação, os impactos negativos são bem menores, tendo em vista a conscientização sobre as atitudes e princípios inerentes a esta modalidade de turismo, aplicados por meio dos conceitos de educação ambiental apresentados.

\section{CONSIDERAÇÕES FINAIS}

O artigo buscou apresentar propostas de requalificação da Fazenda Colubandê. Por possuir extensa área verde, com possibilidades de aproveitamento para o ecoturismo, foram sugeridas algumas possibilidades, para que, aliadas a práticas de educação ambiental, fosse possível sua requalificação, tornando a comunidade participante deste processo, despertando sua consciência para a preservação.

O espaço no qual foi realizada esta pesquisa sofre atualmente com o abandono, assim, o ecoturismo pode ser trabalhado de maneira a conscientizar e propor sua reutilização, incentivando a prática de atividades que possibilitem o lazer, a inclusão social e ações culturais, promovendo a interação com o meio e sua conservação, mediante a experiência direta com a natureza.

A Fazenda Colubandê está inserida em um meio urbano que vem crescendo progressivamente, diminuindo, assim, os espaços naturais. A partir dessa ideia, as ferramentas apresentadas no presente trabalho seriam de grande valia para a comunidade e seu entorno, tendo em vista oferecer benefícios para a cultura, lazer e também melhoria da saúde e qualidade de vida local.

Foi observado que a comunidade já utiliza parte da área para práticas esportivas, o que vem a ser um facilitador para desenvolver as atividades propostas voltadas ao ecoturismo e educação ambiental, porém, é preciso entender que essas ações podem eventualmente não trazer resultados imediatos para aquilo que se espera em termos da requalificação local. Assim, é difícil prever com exatidão os ganhos obtidos a partir da inclusão e conscientização da comunidade para tal proposta. Mesmo assim, apesar dos resultados não serem facilmente mensuráveis, eles poderão ser percebidos no longo prazo.

O principal entrave de uma proposta como esta, seria a falta de recursos e apoio provenientes dos órgãos públicos estaduais e municipais. Fica aberta a possibilidade para que novas pesquisas surjam, a fim de tornar possível a requalificação de outras áreas no município ou mesmo que se aprimorem as ideias propostas para a Fazenda Colubandê, possibilitando novas ações e possíveis correções que venham se fazer necessárias. 


\section{REFERÊNCIAS}

AMAZÔNIA REALIDADE. Evolução Ecoturismo: núcleo de educação ambiental de Acajatuba. Youtube, 14 de out. 2015. Disponivel em: 〈https://www.youtube.com/watch?v=2D6HhpGNizc〉. Acesso em: 10 jan. 2018.

ARAÚJO, P. R. Marco da arquitetura colonial brasileira, Fazenda Colubandê é invadida e saqueada. 0 Globo, 16 de jun. 2016. Disponível em: <https://oglobo.globo.com/rio/bairros/marco-da-arquiteturacolonial-brasileira-fazenda-colubande-invadida-saqueada-16176130\#ixzz4twXateSC stest>. Acesso em: 27 out. 2017.

ARGÔLO, D. S.; BOMFIM, N. R. Relação entre atividade turística, apropriação do território e patrimônio: uma contribuição para o planejamento sustentável do turismo na Bahia. Revista Brasileira de Pesquisa em Turismo. v. 2, n. 3, p. 41-53, nov. 2008.

BELTRÃO, C. Fazenda Colubandê: história, arte, tragédia e descaso (parte I). Arte na Rede. 2017. Disponivel em: http://artenarede.com.br/blog/index.php/fazenda-colubande-historia-artetragediae-descaso-parte-i/. Acesso em: 13 set. 2017.

BRASIL. Diretrizes para uma política nacional de ecoturismo. BARROS II, S. M.; LA PENHA, D. H. M. (Coord.). Brasília: EMBRATUR, 1994. 48 p.

BRASIL. Lei № 9.795, de 27 de abril de 1999. Dispõe sobre a educação ambiental, institui a Política Nacional de Educação Ambiental e dá outras providências. Disponível em: 〈www.planalto.gov.br/ ccivil_03/leis/L9795.htm>.Acesso em: 13 nov. 2017.

BRASIL. Ministério da Educação. Programa Parâmetros em Ação: meio ambiente na escola. Caderno de Apresentação. Brasília: MEC, 2001.

BRASIL. Ministério do Turismo. Ecoturismo: orientações básicas. 2. ed. Brasília, 2010.

CONSELHO NACIONAL DE DESENVOLVIMENTO CIENTífICO E TECNOLÓGICO - CNPq. Consulta Parametrizada. Disponivel em: 〈http://dgp.cnpq.br/dgp/faces/consulta/consulta_parametrizada. jsf〉. Acesso em: 12 nov. 2018.

DIAS, G. F. Educação Ambiental: princípios e práticas. 9. ed. São Paulo: Gaia, 2010.

FERNANDES, M. M. P. Entrevista concedida a Alessandra Lopes Freitas. Niterói, 25 out. 2017.

FERREIRA, A. B. H. Dicionário Aurélio Eletrônico. Versão 7.0. Editora Positivo, 2010. Verbete "revitalização".

INSTITUTO CHICO MENDES DE CONSERVAÇÃO DA BIODIVERSIDADE - ICMBio. Plano de Manejo da Estação Ecológica da Guanabara. Análise da Região da Unidade de Conservação. Encarte 2 - Análise da Região da Estação Ecológica da Guanabara. Disponível em: 〈http://www.icmbio.gov.br/portal/ images/stories/imgs-unidades-coservacao/analise_regiao_ga.pdf〉. Acesso em: 10 jan. 2018.

INSTITUTO DO PATRIMÔNIO HISTÓRICO E ARTÍSTICO NACIONAL - IPHAN. Lista de Bens Tombados processos em andamento 2018. 2018. Disponivel em: 〈http://portal.iphan.gov.br/uploads/ckfinder/ arquivos/Lista_bens_tombados_processos_andamento_2018>. Acesso em: 11 nov. 2018.

KASSOW, I. Fazenda Colubandê. In: PINHO, A. M. de. Cultura RJ: caminhos cheios de bossa por um estado com muita raça e talento. Rio de Janeiro: Pancrom, 2014.

MAGALHÃES, G. W. (Coord.). Pólos de ecoturismo: Brasil. São Paulo: Terragraph, 2001. 
MARINS, P. C. G. Requalificação de Áreas Urbanas no Brasil: caminhos para um balanço crítico em relação às práticas de turismo e lazer. Revista Patrimônio: Lazer e Turismo. 2018. Disponível em: 〈www.unisantos.br/pos/revistapatrimonio/artigos0407.html?cod=15〉. Acesso em: 10 jan. 2018.

MENDONÇA, R. A. Experimentando a sustentabilidade do turismo na natureza. In: TRIGO, L. G. G. (Coord.) Análises regionais e globais do turismo brasileiro. São Paulo: ROCA, 2005. p. 537-545.

MOURA, D. et al. A revitalização urbana: contributos para a definição de um conceito operativo. Cidades, Comunidades e Territórios. n. 12/13, dez. 2006, p. 15-34. Disponível em: 〈http://revistas. rcaap.pt/cct/article/view/9228/6675> Acesso em: 13 nov. 2017.

MUSSARA, R. M. L. M. Patrimônio Cultural, Meio Ambiente e Cidadania. Revista Acesso Livre. 2016, v. 6, n. 6. p. 23-42.

NARVAEZ, E. L. El turismo alternativo: una opción para el desarrollo local. REV IISE, San Juan, v. 6, n. 6, 2014.

NUCCI, T. C. Qualidade Ambiental e Adensamento Urbano: um estudo de ecologia e planejamento da paisagem aplicada ao distrito de Santa Cecília. 2. ed. Curitiba: FAPESP, 2008.

ORGANIZAÇÃO DAS NAÇÕES UNIDAS - ONU. Declaração Final da Conferência das Nações Unidas sobre Desenvolvimento Sustentável (RIO + 20). O Futuro que Queremos. 2012. Disponível em: 〈http://www. rio20.gov.br/clientes/rio20/rio20/documentos/documentos-da-conferencia.htmls. Acesso em: 08 jan. 2018.

O SÃO GONÇALO. Batalhão de Polícia Florestal volta à Fazenda Colubandê em São Gonçalo, 26 de set. 2017. O São Gonçalo. Disponível em: 〈http://www.osaogoncalo.com.br/geral/28157/batalhaode-policia-florestal-volta-a-fazenda-colubande-em-sao-goncalo〉. Acesso em: 13 out. 2017.

PELEGRINI, S. C. A. Cultura e natureza: os desafios das práticas preservacionistas na esfera do patrimônio cultural e ambiental. Revista Brasileira de História. v. 26, n. 51. São Paulo, Jan./June 2006.

PREFEITURA MUNICIPAL DE SÃO GONÇALO - PMSG. Cidade - História de São Gonçalo. 2017. Disponível em: 〈http://www.saogoncalo.rj.gov.br/historia.php〉. Acesso em: 13 out. 2017.

RIO DE JANEIRO (Estado). Autorização Provisória SUBLOP/SEFAZ, $n^{\circ}$ 04/2017. Dispõe sobre Termo de entrega e recebimento de imóvel em favor da Seseg. Diário Oficial do Estado do Rio de Janeiro. 29 de ago. de 2017, $\mathrm{n}^{\circ} 161$, Parte I.

RUSCHMANN, D. V. M. Impactos ambientais do turismo ecológico no Brasil. Revista Turismo em Análise, Brasil, v. 4, n. 1, p. 56-68, mai. 1993. Disponível em: 〈http://www.revistas.usp.br/rta/article/ view/63069 >. Acesso: 16 out. 2017.

SATO, M. Educação para o Ambiente Amazônico. 1997. 239 f. Tese (Doutorado em Educação) Universidade Federal de São Carlos, São Carlos/SP. 1997.

SCHIMANSKI, E.; MOREIRA, J. C.; MORO, P. R. A importância da educação ambiental no processo de defesa do patrimônio natural e cultural: o caso de Piraí da Serra - Paraná, Brasil. Configurações Revista de Sociologia, 11, jun. 2013.

SILVA, G. K. P. et al. (Re)conhecendo o "lugar" de vivência por meio do uso de geotecnologias e trilhas interpretativas: uma experiência no município de Agudo-RS. Geosaberes, Fortaleza, v. 2, n. 3, p. 3-17, 2011.

SILVA, J.; PINHEIRO, J. Análise do projeto de revitalização do patrimônio histórico e cultural da estrada de ferro Madeira-Mamoré. Caderno Virtual de Turismo. Rio de Janeiro, v. 14, n. 2, p. 167-182, ago. 2014. 
SILVA, M. A. et al. Percurso interpretativo do centro histórico Cáceres/MT, para fins turísticos e de educação patrimonial. Revista Brasileira de Pesquisa em Turismo. São Paulo, v. 10, n. 3, p. 435-458, set./dez. 2016.

SOS COLUBANDÊ. História do bairro: fazenda Colubandê. 2017. Disponível em: 〈http://soscolubande. blogspot.com.br/p/historia-do-bairro.html>. Acesso em: 13 out. 2017.

SOTRATTI, M. A. Revitalização. In: REZENDE, M. B. et al. Dicionário Iphan de Patrimônio Cultural. Rio de Janeiro, Brasília: Iphan/DAF/Copedoc, 2015. (verbete). Disponível em: 〈http://portal.iphan.gov. $\mathrm{br} /$ dicionarioPatrimonioCultural/detalhes/58/revitalizacao>. Acesso em: 13 out. 2017. 